\title{
Upgrade Skill Siswa SMK Kadiri Kras dengan Aplikasi Accurate
}

\author{
Rachma Agustina*, Dwi Ari Pertiwi, Meta Ardiana \\ Universitas Hasyim Asy'ari Tebuireng, Jombang, Indonesia \\ *Coresponding Author: rachma.agustina1@gmail.com \\ Dikirim: 05-02-2022; Direvisi: 21-02-2022; Diterima: 24-02-2022
}

\begin{abstract}
Abstrak: Program pengabdian kepada masyarakat ditujukan untuk peningkatan kemampuan siswa SMK dalam memanfaatkan aplikasi accurate untuk penyusunan laporan keuangan. Semakin meningkatnya tuntutan dari dunia kerja, mau tidak mau harus diikuti dengan peningkatan kemampuan siswa selama menempuh proses pembelajaran. Hal ini agar siswa siap menghadapi persaingan dunia kerja dan juga menambah rasa percaya diri siswa dalam menghadapi masa depannya. Pelatihan diikuti oleh 25 siswa kelas XII SMK Kadiri Kras, dari jurusan Akuntansi. Metode pelaksanaan program dengan memberikan materi dan contoh kasus input transaksi pada akun-akun yang tersedia pada aplikasi Accurate, sedangkan siswa langsung mempraktekkan aplikasi tersebut pada komputer di laboratorium sekolah. Pelaksanaan berlangsung dengan lancar dan siswa yang merupakan peserta pelatihan tampak antusias selama proses pelaksanaan, hal ini bisa dilihat dari tanya jawab dan diskusi yang terus berjalan selama program pengabdian kepada masyarakat dilaksanakan.
\end{abstract}

Kata Kunci: aplikasi accurate; siswa SMK; upgrade skill

\begin{abstract}
The community service program is aimed at increasing the ability of vocational students in utilizing the accurate application for the preparation of financial reports. The increasing demands from the world of work, inevitably have to be followed by increasing students' abilities during the learning process. This is so that students are ready to face the competition in the world of work and also increase students' confidence in facing their future. The training was attended by 25 students of class XII of SMK Kadiri Kras, majoring in Accounting. The method of implementing the program is by providing material and examples of transaction input cases on the accounts available in the accurate application, while students practice the application directly on a computer in the school laboratory. The implementation went smoothly and the students who were trainees seemed enthusiastic during the implementation process, this could be seen from the questions and answers and discussions that continued during the community service program.
\end{abstract}

Keywords: accurate application; SMK students; upgrade skills

\section{PENDAHULUAN}

Implementasi perangkat lunak di bidang akuntansi telah menjadi hal yang tidak bisa terpisah dari bisnis sehingga penyiapan tenaga kerja mau tidak mau harus mengikuti kemajuan tersebut. Sumber daya manusia harus memiliki kemampuan untuk mengoperasikan komputer dan memakai software guna bisa membuat olahan bermacam data juga berbagai transaksi, perihal ini sesuai dengan kutipan pernyataan dari Hudha (2017) yang mengungkapkan bahwa pengetahuan pada bidang akuntansi pun mempunyai peranan besar guna majunya suatu usaha yang sedang diolah, bidang pendidikan pun harus ikut serta dalam pembekalan pengetahuan di bidang tersebut. Sebab hal tersebut akan selalu dibutuhkan dan relevan dalam banyak hal (Kusumawardani, et al., 2018). SMK sebagai sekolah kejuruan mempunyai prinsip untuk memberikan keutamaan pada persiapan siswa guna mengisi bidang kerja juga 
harus bisa mendukung berkembangnya profesionalisme dengan memberikan berbagai skill program. Kemampuan soft skill dari lulusan SMK saat ini termasuk masih rendah sehingga pengembangan soft skills merupakan aspek penting dalam menghasilkan lulusan yang mampu bersaing dan berhasil dalam pekerjaaannya (Djashan, 2017). Program-program pengembangan softskills harus bisa disesuaikan dengan apa yang dibutuhkan dunia kerja dan permintaan dari pasar juga masyarakat. Bidang keahlian bisnis dan manajemen yang terlaksana di SMK salah satunya adalah akuntansi keuangan lembaga. Guna menyiapkan tenaga kerja berkualitas, Sekolah Menengah Kejuruan (SMK) mendampingi lulusan dengan sertifikat kompetensi yang diperoleh dengan Ujian Kompetensi Keahlian (UKK), dalam bidang akuntansi keahlian akuntansi dan komputer akuntansi merupakan materi yang diujikan dan ini menjadi syarat utama dalam menentukan kelulusan siswanya (Helmayunita dkk, 2019).

Aplikasi komputer akuntansi dibuat untuk mengotomatisasi transaksi-transaksi ke dalam laporan dan analisis laporan (Diyani dkk, 2019). Dari informasi guru mitra sekolah, selama ini pembelajaran komputer akuntansi yang ada di SMK menggunakan aplikasi MYOB yang merupakan akronim dari Mind your own business, yang merupakan produk Australia (Biduri et al., 2020). Aplikasi ini adalah aplikasi pembukuan (akuntansi) yang ditujukan bagi usaha kecil (UMKM) yang dibangun secara terpadu (Rohmah et al., 2019). Namun di era yang semakin berkembang cepat saat ini, siswa dituntut untuk memahami berbagai aplikasi, salah satunya adalah ACCURATE Versi 5 (Siregar, 2018).

Accurate merupakan nama salah satu aplikasi komputer akuntansi, yang dibuat oleh orang Indonesia kemudian dikembangkan PT. Cipta Piranti Sejahtera tahun 1998, terkenal dengan nama CPSSoft. Produk perdana diluncurkan pada 1999 dengan mengambil nama Accurate 2000. Selanjutnya perusahaan tersebut mengembangkan program accurate dengan berkelanjutan, sesuai yang dibutuhkan user juga ada penyesuaian dengan peraturan standar akuntansi juga aturan pajak di Indonesia. Terakhir versi yang direlease tahun 2016 adalah Accurate 5 yang muncul dengan fiturfitur terbaru lebih praktis, dinamis dan interaktif (Suryani dan Lubis, 2018). Pada release terakhir ini, system pelaporan dan juga pencatatan keuangan juga telah mengikuti standar dari IAI, sedangkan mentode penyusutan juga penilaian persediaan telah mengakomodir ketentuan peraturan pajak Indonesia. Di aplikasi ini juga telah disematkan aplikasi rekonsiliasi pajak guna penentuan PPN kurang dan lebih bayarnya. Kelebihan yang dimiliki oleh ACCURATE antara lain menggunakan database server firebird berbasis SQL (Finatariani et al., 2019). Selain itu dalam aplikasi terbaru ini juga terdapat kemudahan lainnya yaitu, laporan dapat dilihat secara langsung dengan aplikasi microsoft excel, faktur yang dapat di customize oleh user, serta kemudahan dalam urusan perpajakan, karena telah disesuaikan dengan aturan yang ada di Indonesia (Darmanto, 2017).

SMK Kadiri Kras sebagai tempat pelaksanaan program pengabdian kepada masyarakat berlokasi di Desa Kras, Kec. Kras, Kab. Kediri. SMK ini memiliki 3 jurusan, yaitu: tata niaga, teknik komputer jaringan, dan akuntansi. Web https://dapo.dikdasmen.kemdikbud.go.id/ menyebutkan bahwa SMK Kadiri Kras sejauh ini mempunyai sarana prasarana berupa gedung dengan 1 perpustakaan, 8 ruang kelas dan 1 laboratorium komputer. Sanitasi yang digunakan masih dalam batas minim. Penggunaan akses internet terbatas, namun sekolah berkomitmen untuk memanfaatkan sumber daya tersebut dengan semaksimal mungkin untuk menambah 
ketrampilan siswa. Jurusan Akuntansi, pada program pembelajaran masih menggunakan cara manual untuk memasukkan transaksi pada laporan keuangannya.

Pelaksanaan program pengabdian kepada masyarakat memberikan harapan bagi SMK Kadiri Kras guna bisa mengurangi permasalahan tersebut, untuk mempersiapkan siswa dan lulusan agar lebih bisa bersaing di dunia kerja dan menambah rasa percaya diri siswa. Pemecahan masalah yang kemudian ditawarkan pada pelaksanaan PKM bagi SMK adalah:

1. Meningkatkan wawasan siswa mengenai IT terutama pada bidang akuntansi

2. Menambah ketrampilan siswa pada penyusunan financial statement yang berbasis komputer

3. Menambah ketrampilan siswa pada penggunaan aplikasi Accurate

\section{METODE PELAKSANAAN KEGIATAN}

Pelaksanaan program pengabdian kepada masyarakat ini adalah berupa pelatihan penggunaan software accurate accounting. Pemberian materi dalam pelatihan disesuaikan dengan apa yang dibutuhkan siswa SMK Kadiri Kras sebagai peserta, dengan tujuan meningkatkan skill dan pemahaman siswa agar lebih mendalam tentang komputerisasi akuntansi. Mitra dalam pelatihan ini turut berpartisipasi dengan menyediakan laboratorium komputer bagi terlaksananya program pembelajaran dan pelatihan, juga menyiapkan guru pendamping yang membantu tim dalam pelaksanaan PKM.

Kegiatan ini dimulai dengan perencanaan kegiatan dengan menyerahkan proposal kegiatan pada Kepala SMK Kadiri Kras. Selanjutnya pelaksanaan kegiatan dibagi menjadi tiga tahap, yaitu:

1. Persiapan, untuk tahapan ini tim pengabdian dan mitra menyiapkan materi dan juga perangkat-perangkat komputer yang tersedia di laboratorium komputer SMK Kadiri Kras dan menginstal aplikasi accurate.

2. Pelaksanaan, tahapan ini dijalankan pada Rabu, 13 Oktober 2021 bertempat di Laboratorium Komputer SMK Kadiri Kras, dan diikuti oleh 25 peserta yaitu siswa kelas XII jurusan akuntansi. Pada proses pelaksanaan ini terdiri dari kegiatan:

a. Pembukaan kegiatan pelatihan accurate oleh Kepala SMK Kadiri Kras.

b. Pemberian soal pre-test yang telah disusun oleh tim PKM, sebelum peserta menerima materi accurate.

c. Pemberian materi pendahuluan mengenai fitur-fitur yang terdapat pada accurate.

d. Memberikan materi tentang input transaksi dengan langsung memberikan studi kasus transaksi-transaksi yang tercover dalam software accurate, materi tersebut adalah:

- Mempersiapkan database awal

- Proses menginput transaksi pada modul penjualan

- Proses menginput transaksi pada modul pembelian

- Proses menginput transaksi pada modul kas

- Proses menginput transaksi pada bank

- Proses inputing transaksi pada jurnal umum

- Mengecek kembali laporan keuangan yang sudah tersusun

3. Evaluasi, Betwan (2019) mengungkapkan bahwa evaluasi merupakan bagian dari pendidikan sehingga perencanaan atau penyusunan, pelaksanaan, dan pendayagunaanpun tidak dapat dipisahkan dari keseluruhan program pendidikan, 
begitupun pada kegiatan pengabdian kepada masyarakat ini. Setelah pemberian materi dan latihan input transaksi pada Accurate Accounting Software selesai dilaksanakan. Peserta diberikan waktu untuk mengulang sendiri materi-materi yang sudah disampaikan, sambal menanyakan apabila dirasa ada materi yang tidak dimengerti oleh peserta. Sesudah peserta memahami setiap langkah yang diperlukan dalam inputing transaksi, selanjutnya diadakan post-test dengan soal yang telah disusun oleh Tim PKM.

Pemateri dalam pelatihan ini adalah Dwi Ari Pertiwi, SE., S.Pd., MM. dengan latar belakang di bidang akuntansi. Selama pemberian materi siswa juga didampingi dengan guru dari mitra, tim dosen dan mahasiswa, dari awal persiapan sampai evaluasi selesai dilaksanakan.

\section{IMPLEMENTASI KEGIATAN DAN PEMBAHASAN}

Pengukuran keberhasilan kegiatan pengabdian perlu dirumuskan dengan indikator-indikator yang telah ditentukan sebagai tolok ukur keberhasilan. Tingkat keberhasilan kegiatan pengabdian diukur menggunakan kuesioner pre-test dan posttest atau sebelum dan setelah pelatihan (Kurnianingsih et al., 2017). Kuesioner yang diberikan berbentuk cetak/print-out yang berisi tes pengujian kemampuan komputerisasi akuntansi. Pengukuran ini bertujuan guna mengetahui kemampuan komputerisasi akuntansi para peserta pelatihan sebelum dan sesudah dilaksanakan pelatihan. Penilaian melihat dari prosentase besaran jawaban dari peserta pelatihan dengan option jawaban "ya" dan "tidak", yang hasilnya sebagai berikut:

Tabel 1. Respon Peserta Pelatihan Accurate Accounting Software

\begin{tabular}{clcc}
\hline \multirow{2}{*}{ No } & \multicolumn{2}{c}{ Aspek yang dinilai } & \multicolumn{2}{c}{ Test } \\
& & $\begin{array}{c}\text { Pre } \\
\text { test }\end{array}$ & $\begin{array}{c}\text { Post } \\
\text {-test }\end{array}$ \\
\hline 1 & Peserta paham mengenai komputerisasi akuntansi & $40 \%$ & $80 \%$ \\
\hline 2 & Peserta paham tentang perkembangan komputer akuntansi & $50 \%$ & $70 \%$ \\
\hline 3 & Peserta pernah mengoperasikan software akuntansi & $30 \%$ & $80 \%$ \\
\hline 4 & Peserta memahami fitur-fitur software akuntansi (accurate) & $30 \%$ & $80 \%$ \\
\hline 5 & Peserta memahami keunggulan-keunggulan software akuntansi & $30 \%$ & $80 \%$ \\
\hline 6 & Kesulitan peserta dalam mengaplikasikan software akuntansi & $80 \%$ & $20 \%$ \\
\hline 7 & Penggunaan sumber informasi dalam mengaplikasikan & $20 \%$ & $80 \%$ \\
\hline 8 & Poftware akuntansi & $40 \%$ & $90 \%$ \\
\hline 9 & Keserta memahami pentingnya database & $30 \%$ & $90 \%$ \\
\hline 10 & Peserta mendapatkan manfaat dari pelatihan accurate & $90 \%$ \\
\hline
\end{tabular}

Dari hasil penilaian, terdapat perbedaan skor yang signifikan pada saat dilakukan tes sebelum dan sesudah pelatihan dilaksanakan. Perbedaan dan peningkatan jawaban ini menunjukkan bahwa peserta merasakan bertambahnya pengetahuan mengenai komputerisasi akuntansi, terutama software Accurate, dan beranggapan bahwa pelatihan ini sangat bermanfaat bagi siswa sebagai peserta pelatihan. Tentu saja perihal ini bisa dianggap sesuai dengan pernyataan dari Knapp (2016) bahwa: "Jika post-test adalah tes kognitif yang merupakan tes yang sama dengan pretest, pertanyaannya mungkin sudah biasa. Jadi jika skor meningkat dari pre-test ke post-test, hal ini 
merupakan dampak/efek diberikannya latihan/treatment kepada objek yang diuji. Sesuai dengan hasil kegiatan pengabdian yang dilaksanakan oleh Utama, A, A, G, S., \& Pratama, D. (2020) bahwa terdapat peningkatan pengetahuan dan juga skill para peserta dalam mengaplikasikan ACCURATE Versi 5, sebagai alat bantu dalam memperlancar proses pembelajaran di sekolah para peserta. Hasil pengabdian dapat dilihat dari perubahan yang terlihat pada hasil kuisioner saat pra acara dan juga pasca acara.

Hasil dari kuesioner tersebut sejalan dengan kegiatan serupa yang telah dilaksanakan oleh Culita et.al. (2020) yang menyatakan bahwa sebagian besar peserta merasakan manfaat dan para peserta antusias serta berpartisipasi secara penuh dalam mengikuti semua rangkaian pelaksanaan kegiatan. Hal ini terlihat dari keaktifan mereka dalam menyelesaikan test yang diberikan oleh tim sampai dengan sesi akhir dan sebagian besar dari mereka memahami konsep akuntansi dengan Accurate. Begitupun Khairani, et.al (2021) dengan hasil bahwa ada penambahan pemahaman dan keahlian peserta pelatihan terhadap aplikasi accurate juga kegiatan ini mendapat respon positif dari para guru dan beberapa siswa yang menjadi peserta pelatihan yang dibuktikan dengan antusiasme kehadiran dari peserta.

Hasil pertanyaan deskriptif menyangkut pelaksanaan pelatihan, diperoleh jawaban yang beragam terkait pertanyaan:

1. Metode pelatihan yang digunakan dalam pelatihan, rata-rata peserta lebih menyukai sistem yang sudah dilaksanakan saat ini oleh tim PKM, yaitu dengan pemberian contoh kasus dan transaksi langsung diinput dalam berbagai akun sesuai yang dibutuhkan.

2. Pentingnya hal-hal yang perlu ditekankan dalam pelaksanaan pelatihan komputer akuntansi, mayoritas peserta meminta ada tambahan materi atau tambahan latihan di lain kesempatan dengan pendampingan kembali agar lebih paham terhadap accurate.

3. Apakah pelatihan Accurate yang dilakukan selama kurang lebih empat jam cukup bagi peserta untuk memahami setiap fungsi dari fitur Accurate. Untuk pertanyaan ini peserta merasa belum cukup dan seperti pada pertanyaan sebelumnya peserta berharap ada kesempatan lagi untuk menambah materi dan menambah latihan tugas, dengan tetap didampingi tim PKM. Hal tersebut sejalan dengan hasil kegiatan dari Suryani, et.al. (2020) bahwa diperlukan penambahan waktu pelaksanaan akan menjadi lebih baik agar penerimaan materi oleh peserta akan menjadi lebih optimal. Diharapkan penyelenggaraan kegiatan workshop ini dilakukan secara berkesinambungan agar kesiapan siswa menghadapi dunia kerja tercapai

4. Apakah Tim Akuntansi Fakultas Ekonomi Universitas Hasyim Asy'ari Tebuireng Jombang sudah memberikan pelatihan Accurate dengan baik. Pertanyaan ini dijawab dengan mayoritas peserta menganggap sudah baik dan bisa dipahami juga didampingi sampai proses input selesai.

5. Apakah saudara berminat apabila Tim Akuntansi Fakultas Ekonomi Universitas Hasyim Asy'ari Tebuireng Jombang kembali memberikan pelatihan Accurate lebih lanjut. Mayoritas peserta menjawab pertanyaan ini dengan ketertarikan yang tinggi dan berharap selain accurate ada lagi materi-materi pengayaan yang diberikan Tim PKM sehingga peserta mendapatkan tambahan ilmu dan ketrampilan yang memadai sebelum mereka benar-benar lulus.

6. Secara keseluruhan, apakah saudara puas dengan pelatihan Accurate yang diberikan oleh Tim Akuntansi Fakultas Ekonomi Universitas Hasyim Asy'ari Tebuireng 
Jombang? Mitra dan juga peserta berpendapat bahwa mereka puas dan mendapatkan manfaat yang besar dengan pelatihan yang diselenggarakan Tim PKM Prodi Akuntansi Fakultas Ekonomi Universitas Hasyim Asy'ari Tebuireng Jombang.

7. Apa saran yang ingin saudara sampaikan kepada Tim Akuntansi Fakultas Ekonomi Universitas Hasyim Asy'ari Tebuireng Jombang terkait dengan pelatihan Accurate agar lebih baik ke depannya? Peserta juga mitra sekolah berharap agar mendapatkan kesempatan lagi untuk memperoleh materi tambahan juga pendampingan untuk kasus-kasus dan materi-materi yang lain, semisal tentang pajak dan ilmu akuntansi lainnya.

Berikut dokumentasi selama pelaksanaan program Pengabdian Kepada Masyarakat di SMK Kadiri Kras, dengan tema "Upgrade Skill Siswa Smk Kadiri Kras Dengan Pemanfaatan Accurate Accounting Software".

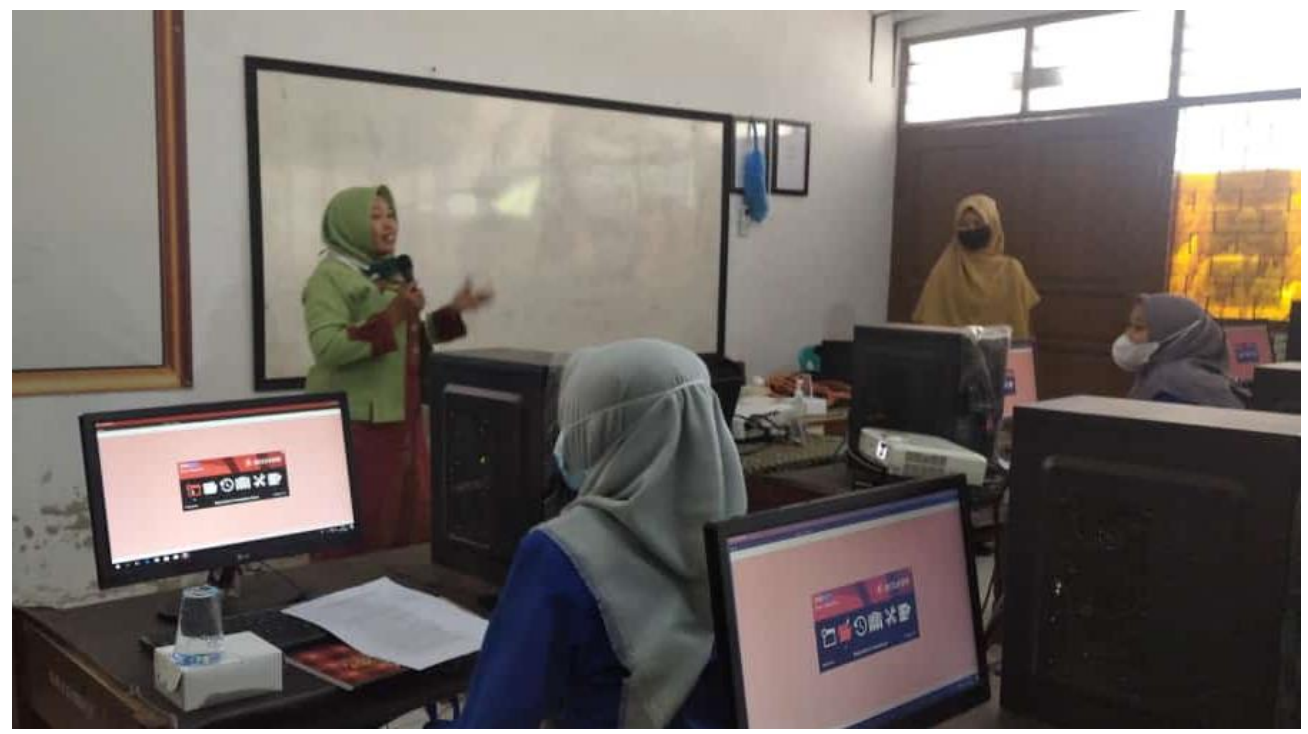

Gambar 1. Proses Pengenalan Fitur-Fitur dalam Accurate

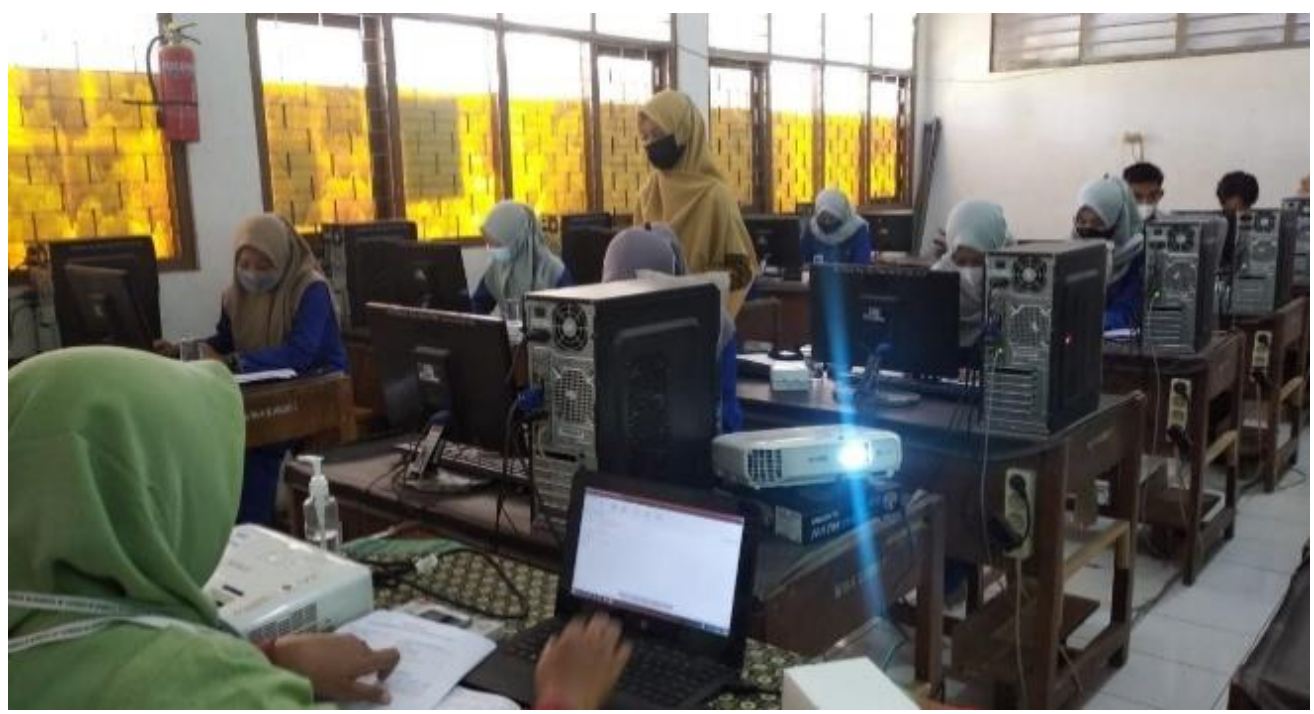

Gambar 2. Pendampingan dari Dosen dan Mahasiswa selama Pelaksanaan

@2022 Bima Abdi (https://jurnal.bimaberilmu.com/index.php/ba-jpm) 


\section{KESIMPULAN}

Hasil dari dilaksanakannya program Pengabdian Kepada Masyarakat ini adalah:

- Peserta, yang merupakan siswa kelas XII SMK Kadiri Kras jurusan Akuntansi mendapatkan tambahan ilmu dan ketrampilan yang memadai

- Peserta dan mitra sekolah memberikan tanggapan yang positif dan mendukung untuk program yang dilaksanakan, juga berharap masih bisa mendapatkan kesempatan untuk kembali mengikuti program-program dari Tim PKM Prodi Akuntansi

- Mitra sekolah yaitu SMK Kadiri Kras memberikan dukungan dengan menyediakan laboratorium komputer, dan membantuk tim PKM pada setiap tahapan kegiatan.

\section{DAFTAR PUSTAKA}

Betwan, B. (2019). Pentingnya Evaluasi Afektif Pada Pembelajaran Pai Di Sekolah. Al-Fikri: Jurnal Studi dan Penelitian Pendidikan Islam, 2(1), 45-60.

Biduri, S., Mulyadi, A., Choiriyah, I. U., \& Sidoarjo, U. M. (2020). Pendampingan Implementasi Sistem Pencatatan Akuntansi Sekolah Bagi Dan Smk Nurul Huda Kepadangan Kabupaten Sidoarjo. Jurnal Terapan Abdimas, 5 No 1(Januari), 114-118.

Culita, C., Salsabila, Z., \& Marpaung, S. H. (2020). Pelatihan Komputer Akuntansi Dasar Dengan Software Accurate Pada SMA Husni Thamrin Medan. Jurnal Pendidikan Dan Pengabdian Masyarakat, 3(4).

Darmanto. (2017). Media Altenatif Software Praktikum Akuntansi SMK berbasis Open Source. In Seminar Nasional Ilmu Terapan (SNITER) 2017 - Universitas Widya Kartika, 1-6.

Diyani, L.K., Rahman, H.A., dan Wijaya, I. (2019). Peningkatan Kemampuan Komputerisasi Akuntansi Perusahaan Dagang Menggunakan "Accurate". APTEKMAS Vol. 2 No. 1 (2019). DOI: http://dx.doi.org/10.36257/apts.v2i1

Djashan, I.A. 2017. Peningkatan Kualitas Lulusan Siswa Melalui Pelatihan Komputer Akuntansi Dasar Berbasiskan Accurate. Jurnal Sakai Sambayan. Vol. 1, No. 3.

Finatariani, E., Darsita, I., Ekonomi, F., \& Pamulang, U. (2019). Peningkatan Kemampuan Bersaing Di Dunia Kerja Dengan Pelatihan Software Zahir Accounting. Abdimisi, 1(1), 63-68.

Helmayunita, N., Serly, V., dan Honesty, H. N.,. (2019). PKM Peningkatan Kompetensi Guru SMK Dalam Bidang Komputer Akuntansi. Wahana Riset Akuntansi. Vol. 7, No. 2.

Hudha, C. (2017). Pengaruh tingkat pendidikan, pengetahuan akuntansi dan pelatihan akuntansi terhadap penggunaan informasi akuntansi dimoderasi ketidakpastian lingkungan usaha kecil menengah. Jurnal Ekonomi Pendidikan dan Kewirausahaan, 5(1), 68-90.

Khairani, S. et.al. (2021). Pelatihan Aplikasi Accurate Bagi Guru dan Siswa SMK Negeri 1 Palembang. Publikasi Hasil Pengabdian kepada Masyarakat (PADIMAS), 1(1). 
Knapp, T. R. (2016). Why is the one-group pretest-posttest design still used?

Kurnianingsih I, Rosini, Ismayati N. (2017). Upaya Peningkatan Kemampuan Literasi Digital bagi Tenaga Perpustakaan Sekolah dan Guru di Wilayah Jakarta Pusat Melalui Pelatihan Literasi Informasi. Jurnal Pengabdian Kepada Masyarakat. (Indonesian Journal of Community Engagement), 3(1), 61-76

Kusumawardani, A., Irwansyah, I., Setiawati, L., Ginting, Y. L., \& Khairin, F. N. (2018). Urgensi Penerapan Pendidikan Akuntansi Berbasis Akuntansi Sosial Dan Lingkungan. Ekuitas (Jurnal Ekonomi dan Keuangan), 2(1), 65-82.

Rohmah, M., Dewi, T. R., \& Amaliah, K. (2019). Upaya Peningkatan Kemampuan Siswa dalam Menggunakan Aplikasi Myob Accounting di SMK Negeri 1 Belitang Madang Raya. Jurnal Indonesia Mengabdi, 1(2), 57-59.

Siregar, I. F. (2018). Pelatihan Penggunaan Aplikasi Komputer Akuntansi Sebagai Media Untuk Meningkatkan Kompetensi Dan Pembelajaran Bagi Guru Dan Siswa SMK N 1 Tapung Pekanbaru. Jurnal Manajemen Pendidikan Dan Pelatihan, 2(3), 227-232.

Suryani, et.al. (2020). Workshop Komputer Akuntansi Accurate Versi 5 Bagi Guru Dan Siswa Akuntansi SMK Triguna 1956 Jakarta Selatan. JAMAIKA: Jurnal Abdi Masyarakat Program Studi Teknik Informatika Universitas Pamulang. Vol. 1, No. 2.

Suryani., Lubis, I. (2018). Accurate 5 \& EFaktur Ed 3. Jakarta: STAPI Indonesia Publishing. ISBN : 9786025161803

Utama, A, A, G, S.,\& Pratama, D. (2020). Pelatihan Accurate Bagi Guru SMA/SMK Se-Kabupaten Banyuwangi. Jurnal Solma, 09(2), 316-322. Doi: http://dx.doi.org/10.22236/solma.v9i2.4892.

Zeinora, Septariani, D. (2020). Analisis Kelebihan dan Kekurangan Serta Kebermanfaatan Menggunakan Software Accurate, MYOB, Zahir Accounting dan Penerapannya di Universitas Indraprasta PGRI. JABE (Journal of Applied Business and Economics), 6(4), 341-353. 